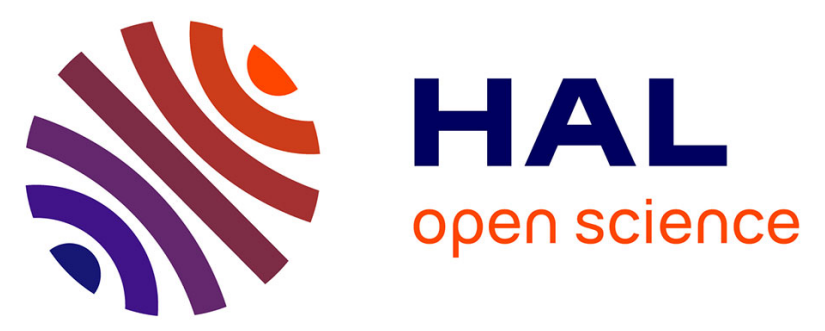

\title{
Regioselective hydrosilylation of terminal alkynes using pentamethylcyclopentadienyl iridium(III) metallacycle catalysts
}

Yann Corre, Christophe Werlé, Lydia Brelot-Karmazin, Jean-Pierre Djukic, Francine Agbossou-Niedercorn, Christophe Michon

\section{To cite this version:}

Yann Corre, Christophe Werlé, Lydia Brelot-Karmazin, Jean-Pierre Djukic, Francine AgbossouNiedercorn, et al.. Regioselective hydrosilylation of terminal alkynes using pentamethylcyclopentadienyl iridium(III) metallacycle catalysts. Journal of Molecular Catalysis A: Chemical, 2016, 423 (45), pp.256 - 263. 10.1016/j.molcata.2016.07.014 . hal-01715061

\section{HAL Id: hal-01715061 \\ https://hal.science/hal-01715061}

Submitted on 2 Jan 2022

HAL is a multi-disciplinary open access archive for the deposit and dissemination of scientific research documents, whether they are published or not. The documents may come from teaching and research institutions in France or abroad, or from public or private research centers.
L'archive ouverte pluridisciplinaire HAL, est destinée au dépôt et à la diffusion de documents scientifiques de niveau recherche, publiés ou non, émanant des établissements d'enseignement et de recherche français ou étrangers, des laboratoires publics ou privés. 


\title{
Regioselective hydrosilylation of terminal alkynes using pentamethylcyclopentadienyl iridium(III) metallacycle catalysts
}

Yann Corre, ${ }^{\mathrm{a}, \mathrm{b}}$ Christophe Werlé, ${ }^{\mathrm{c}}$ Lydia Brelot-Karmazin, ${ }^{\mathrm{c}}$ Jean-Pierre Djukic, ${ }^{\mathrm{c}}$ Francine Agbossou-Niedercorn, ${ }^{* a, b}$ Christophe Michon*a,b

\footnotetext{
${ }^{a}$ Univ. Lille, CNRS, Centrale Lille, ENSCL, Univ. Artois, UMR 8181 - UCCS - Unité de Catalyse et Chimie du Solide, F-59000 Lille, France.

${ }^{\mathrm{b}}$ Unité de Catalyse et de Chimie du Solide, CNRS UMR 8181, Ecole Nationale Supérieure de Chimie de Lille, Bât C7, Av. Mendeleïev, Cité Scientifique, CS 90108, Villeneuve d'Ascq Cedex, France

${ }^{c}$ Institut de Chimie de Strasbourg, UMR 7177, Université de Strasbourg, 4 rue Blaise Pascal, F-67000 Strasbourg, France

christophe.michon@ensc-lille.fr,francine.agbossou@ensc-lille.fr

Fax: (+)33-320436561, Tel.: (+)33-320436863
}

\begin{abstract}
Pentamethylcyclopentadienyl iridium(III) metallacycles catalyse the hydrosilylation of alkynes using triethylsilane and no additive. The reactions proceed rapidly and efficiently at low catalyst loadings and under mild reaction conditions. If catalyses starting from terminal alkynes lead selectively to $(Z)$-alkenylsilanes in high yields, reactions are less efficient and selective starting from internal alkynes due to steric hindrance and the possible formation of isoquinolinium salts. Mass spectrometry highlights up to two consecutive 1,2-insertions of alkynes could take place into the catalyst iridium-carbon bond.
\end{abstract}

Keywords: iridium; metallacycles; half-sandwich; hydrosilylation, alkynes.

\section{Introduction}

Selective reduction of alkynes to alkenes is an important reaction in organic and polymer chemistry [1]. If semihydrogenation of alkynes has been successfully studied mainly by Lindlar reduction [2], the metal-catalysed hydrosilylation of alkynes is an interesting direct and atom-economic reaction which provides versatile alkenylsilanes [3]. However, the control of the reaction's stereo- and regiochemistry remains challenging depending on several factors like the structure of the catalyst, the nature of reagents (e.g. alkyne and silanes) and reaction parameters (e.g. solvent and temperature). The hydrosilylation of terminal alkynes shall lead to $\beta-(E)$ - and less frequent $\beta$-(Z)-linear vinylsilanes, through respectively anti-Markovnikov 
syn-addition and anti-Markovnikov anti-addition [3n,v]. Futhermore, the synthesis of branched $\alpha$-vinyl silanes through Markovnikov addition is rare [3a,o,u].

The stereoselective synthesis and reactivity of metallacycles like iridium(III) complex $\mathbf{1}$ and chromiumtricarbonylbound iridacycle $\mathbf{2}$ have been studied by some of us for several years (Scheme 1) [4]. Complexes of type 2 were found to display novel catalytic properties for the conversion of terminal aromatic alkynes into racemic $N$-phenyl, 1-arylethylamines by tandem hydroamination and hydrosilylation/protodesilation reactions under mild "one pot" conditions (Scheme 2 a) [5].

Scheme 1 .

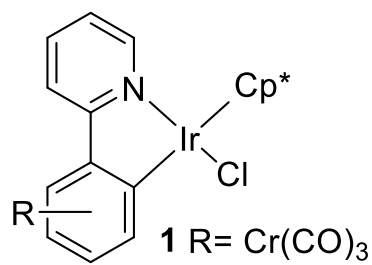

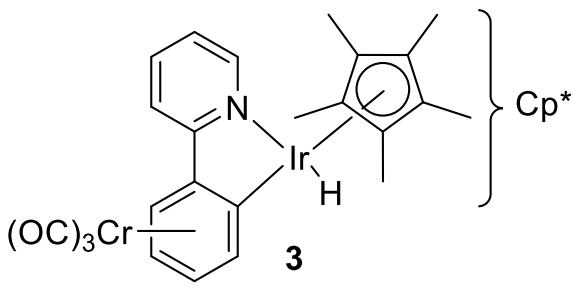
$2 R=-$

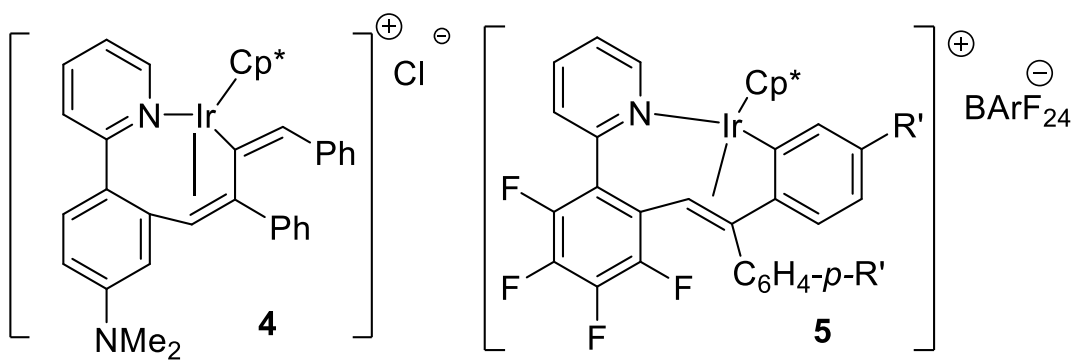

(a)

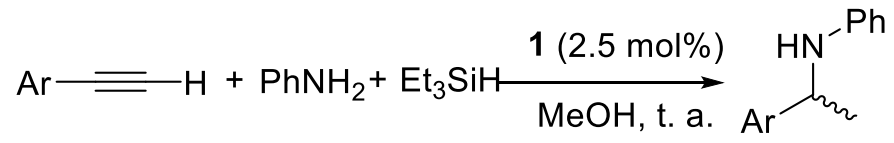

$50-90 \%$ yield

(b)

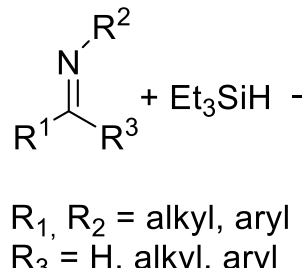

Scheme 2 .$$
1 \text { or } 2(0.01-1 \mathrm{~mol} \mathrm{\%})
$$$$
\underset{\mathrm{NaBArF}_{24}(0.02-2 \mathrm{~mol} \%)}{\mathrm{CH}_{2} \mathrm{Cl}_{2}}
$$$$
25-40{ }^{\circ} \mathrm{C}, 0.25-24 \mathrm{~h}
$$$$
37-100 \% \text { yield }
$$

The peculiar efficiency of such catalysts in promoting hydrosilylation was assigned to the intervention of iridium-hydrido intermediate 3 (Scheme 1) [4e,5,6], a key species for the transfer of the hydritic $\mathrm{H}$ atom to the electrophilic imine substrate. Recently, we showed the combination of iridacycle $\mathbf{1}$ with sodium tetrakis(3,5-trifluoromethyl)phenyl]borate, $\mathrm{NaBArF}_{24}$, as an additive could catalyse the hydrosilylation of various ketimines and aldimines at low catalyst loadings and under mild reaction conditions (Scheme 2 b) [7]. 
Finally, other reports stated the efficiency of such iridacycles for other reactions [8] like hydrogenation [9] and transfer hydrogenation [10]. Regarding the reactivity of iridacycles with alkynes, we and others demonstrated complexes of type 4 could be obtained from a double 1,2-insertion of a terminal aromatic alkyne like phenylacetylene (Scheme 1) [5,11]. A recent report have revealed such 1,2-alkyne insertion could compete with a vinylidene rearrangement/1,1-insertion depending the nature of the iridium(III) metallacycle. Indeed, the reaction of fluorinated iridacycles with diphenylacetylene derivatives was shown to afford ninemembered metallacycle complexes of type $\mathbf{5}$ by way of a sequential vinylidene rearrangement, 1,1-insertion of the vinylidene ligand, and the 1,4-iridium migration to the $\mathrm{Ar}$ group (Scheme 1) [11a]. Considering our previous results on hydrosilylation of imines as well as on tandem hydroamination-hydrosilylation reactions, we investigated iridium(III) metallacycles as catalysts for the hydrosilylation of alkynes.

\section{Results and discussion}

Screening of reaction conditions (e.g. solvent, temperature, time) and catalysts was performed on the hydrosilylation of phenylacetylene $6 \mathbf{a}$ with triethylsilane (Table 1). Among the various solvents screened, tetrahydrofuran (THF) led to a moderate yield and a poor selectivity (entry 1). If the use of toluene and 1,4-dioxane afforded higher yields and a selectivity for (E)-product 8a (entries 2-4), acetonitrile allowed the reaction to proceed well in favor of the (Z)-product 7a provided the reaction temperature was kept at $80^{\circ} \mathrm{C}$ for 20 hours, yields being barely not improved at $100^{\circ} \mathrm{C}$ (entries 5, 6). By comparison, chlorinated solvents had to be preferred considering reactions proceeded well at $40^{\circ} \mathrm{C}$ in favor of $(Z)$-product $7 \mathbf{a}$. If dichloromethane led to an almost quantitative yield and a fair selectivity for $7 \mathbf{a}$ in 20 hours without the use of $\mathrm{AgBF}_{4}$ or $\mathrm{NaBArF}_{24}$ (entries 7, 8, 9), 1,1',2,2'-tetrachloroethane gave better results in only 2 hours (entry 10). Finally, alcohols could not be used because of their spontaneous reactivity with silanes. Hence, as already noticed in our previous studies [4,5,7], a strong polar solvent had to be preferred to activate the catalyst by dissociation of the $\mathrm{Ir}-\mathrm{Cl}$ bond. Though the use of acetonitrile, a greener solvent, afforded fair yields and selectivities at $80^{\circ} \mathrm{C}$ and 20 hours of reaction, the non-coordinating dichloromethane and 1,1',2,2'tetrachloroethane led to better results in only few hours. In presence of our iridium(III) catalysts, nitrile solvents had another drawback due to their reactivity with silane reagents at high temperatures (entries 5,6) [5,7]. Within the most efficient and selective reaction conditions, catalyst $\mathbf{1}$ proved to be slightly more active than catalyst $\mathbf{2}$ (entries 10,11). Yield and selectivity were also high using 1 mol\% of catalyst 1 though the reaction time had to be 
extended to 3 hours (entries 12,13). A preliminary kinetic study performed at $40^{\circ} \mathrm{C}$ and 1 mol\% catalyst loading allowed us to determine a half-life of 1.6 hour (94 minutes) along with a turnover number (TON) of 50 and a turnover frequency (TOF) of 31 . However, the data could not be fitted with any simple kinetic law. A further decrease of the catalyst loading to $0.1 \mathrm{~mol} \%$ led to a much slower reaction with a slightly reduced yield and a significant increase of TON and TOF values (entry 14). However, decreasing the amount of catalyst to $0.01 \mathrm{~mol} \%$ resulted in a very low yield and showed the catalyst limits (entry 15).

Table 1: hydrosilylation of phenylacetylene 6a - effects of solvent, temperature and time.

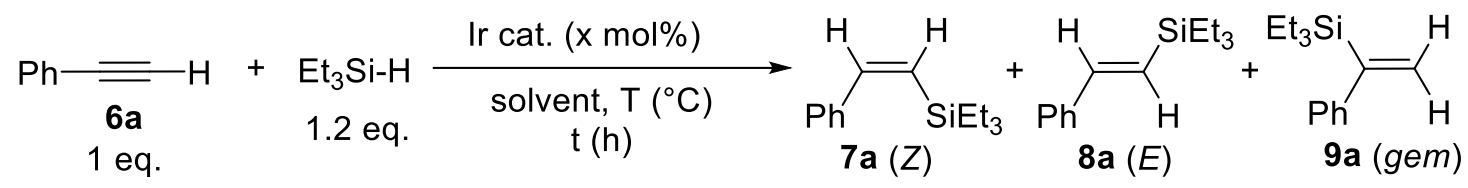

\begin{tabular}{|c|c|c|c|c|c|c|c|c|c|c|}
\hline \multirow{2}{*}{$\begin{array}{c}\text { Entry } \\
1\end{array}$} & \multirow{2}{*}{$\begin{array}{c}\begin{array}{c}\text { Cat. } \\
(\%)\end{array} \\
1(2.5)\end{array}$} & \multirow{2}{*}{$\begin{array}{c}\text { Solvent } \\
\text { THF }\end{array}$} & \multirow{2}{*}{$\begin{array}{c}\mathbf{T} \\
\left({ }^{\circ} \mathbf{C}\right)\end{array}$} & \multirow{2}{*}{$\begin{array}{c}\mathbf{t} \\
(\mathbf{h}) \\
20\end{array}$} & \multirow{2}{*}{$\begin{array}{c}\frac{\text { Yield }}{(\%)^{[a]}} \\
39\end{array}$} & \multicolumn{3}{|c|}{$\begin{array}{c}\text { Selectivity }^{[\mathbf{a}]} \\
(Z) /(\text { E) / ( gem) }\end{array}$} & \multirow{2}{*}{$\begin{array}{c}\mathbf{T O N}^{[\mathbf{b}]} \\
16\end{array}$} & \multirow{2}{*}{$\begin{array}{c}\text { TOF }^{[\mathbf{c}]} \\
0.8\end{array}$} \\
\hline & & & & & & 51 & 41 & 8 & & \\
\hline 2 & $1(2.5)$ & toluene & 80 & 20 & 83 & 37 & 57 & 7 & 33 & 1.7 \\
\hline 3 & $\mathbf{1}(2.5)$ & toluene & 100 & 10 & 87 & 21 & 71 & 8 & 35 & 3.5 \\
\hline 4 & $1(2.5)$ & $\operatorname{dioxane}^{[\mathrm{d}]}$ & 80 & 20 & 85 & 1 & 91 & 7 & 34 & 1.7 \\
\hline 5 & $1(2.5)$ & $\mathrm{CH}_{3} \mathrm{CN}$ & 80 & 20 & 72 & 89 & 8 & 3 & 29 & 1.5 \\
\hline 6 & $1(2.5)$ & $\mathrm{CH}_{3} \mathrm{CN}$ & 100 & 20 & 78 & 0 & 92 & 8 & 31 & 1.6 \\
\hline 7 & $1(2.5)$ & $\mathrm{CH}_{2} \mathrm{Cl}_{2}$ & 40 & 20 & 95 & 83 & 12 & 5 & 38 & 1.9 \\
\hline 8 & $1(2.5)$ & $\mathrm{CH}_{2} \mathrm{Cl}_{2}$ & 40 & 2 & 57 & 92 & 3 & 5 & 40 & 20 \\
\hline $9^{[\mathrm{e}]}$ & $1(2.5)$ & $\mathrm{CH}_{2} \mathrm{Cl}_{2}$ & 40 & 20 & 0 & - & - & - & - & - \\
\hline 10 & $\mathbf{1}(2.5)$ & TCE & 40 & 2 & 91 & 92 & 6 & 2 & 36 & 18 \\
\hline 11 & $2(2.5)$ & TCE & 40 & 2 & 86 & 91 & 9 & 0 & 36 & 18 \\
\hline 12 & $1(1.0)$ & TCE & 40 & 2 & 71 & 86 & 9 & 5 & 71 & 36 \\
\hline 13 & $1(1.0)$ & TCE & 40 & 3 & 90 & 86 & 9 & 5 & 90 & 30 \\
\hline 14 & $\mathbf{1}(0.1)$ & TCE & 40 & 20 & 87 & 81 & 13 & 6 & 870 & 44 \\
\hline $15^{[\mathrm{f}]}$ & $1(0.01)$ & TCE & 40 & 62 & 11 & 8 & 3 & 0 & 11 & 0.2 \\
\hline
\end{tabular}

[a] determined by ${ }^{1} \mathrm{H}$ NMR using 1,3,5-trimethoxybenzene as an internal reference. [b] Turnover number $=\mathrm{mol}$ of product $/ \mathrm{mol}$ of catalyst. [c] Turnover frequency $=$ mol of product $/ \mathrm{mol}$ of catalyst/hour. [d] 1,4-dioxane. [e] reaction with $5 \mathrm{~mol} \%$ of $\mathrm{AgBF}_{4}$ or $\mathrm{NaBArF}_{24}$, sodium tetrakis(3,5trifluoromethyl)phenyl]borate. [f] $10 \mathrm{~mL}$ solvent and 0.1 eq. of 1,3,5-trimethoxybenzene.

Various silane reagents [12] could be used for the hydrosilylation of phenylacetylene 6a (Table 2). Interestingly, reactions using affordable triethylsilane could be run in 2 hours and at $40^{\circ} \mathrm{C}$ affording (Z)-product in good yield, selectivity, TON and TOF (entry 1). However, an increase of temperature and time resulted in the partial isomerization of $(Z)$ product 7a into (E)-product 8a (entry 2). Within the same reaction conditions (e.g. 2 hours and $40^{\circ} \mathrm{C}$ ), the reaction with triphenylsilane allowed also the selective hydrosilylation of $\mathbf{6 a}$ 
into $(Z)$-product 7a but in lower yield, TON and TOF. An increase of the reaction time and temperature led to the complete isomerization of $\mathbf{7 a}$ into $(E)$-product $\mathbf{8 a}$ (entries 3,4 ). If sterically hindered 1,1,1,3,5,5,5-heptamethyltrisiloxane afforded selectively (Z)-product 7a at $60^{\circ} \mathrm{C}$ in 20 hours, a double reaction time led exclusively to the $(E)$-product 8a (entries 5, 6). Otherwise, the use of triethoxysilane required a stronger heating and showed only the $(E)$ product formation (entries 7, 8). Finally, inexpensive hydrosilylation reagents like tetramethyldisiloxane (TMDS) and polymethylhydroxysiloxane (PMHS) led to complex mixtures (entries 9, 10).

The reaction scope was then studied using the best silane reagent and reaction conditions (Table 3). The hydrosilylation of phenylacetylene 6a proceeded in fair yields at $40^{\circ} \mathrm{C}$ with high selectivities for (Z)-product 7a using triethyl- or triphenylsilane. If the use of triethylsilane led to the $(Z$ )-alkenylsilane $\mathbf{7 b}$ from para-fluorinated reagent $\mathbf{6 b}$ in good yield and selectivity, triphenylsilane afforded only the $(E)$-product $\mathbf{8 b}$ in a modest yield.

Table 2: hydrosilylation of phenylacetylene $\mathbf{6 a}$ - effects of silanes and temperature.

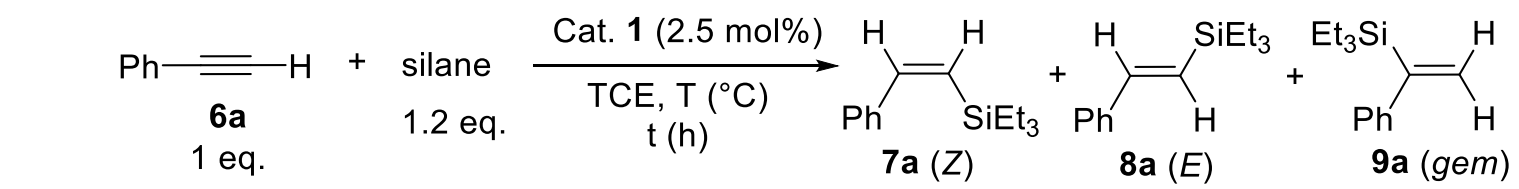

\begin{tabular}{|c|c|c|c|c|c|c|c|c|c|c|}
\hline Entry & Silane & $\begin{array}{c}\operatorname{Cost}^{[\mathrm{a}]} \\
\left(€ / \mathrm{mmol}^{2}\right)\end{array}$ & $\begin{array}{c}\mathbf{T} \\
\left({ }^{\circ} \mathbf{C}\right)\end{array}$ & $\begin{array}{c}\text { t } \\
\text { (h) }\end{array}$ & $\begin{array}{l}\text { Yield } \\
(\%)^{[b]}\end{array}$ & $\begin{array}{c}\text { Sel } \\
(Z) /\end{array}$ & $\begin{array}{l}\text { ctivit } \\
E) /(\end{array}$ & & $\mathrm{TON}^{[\mathrm{c}]}$ & TOF $^{[d]}$ \\
\hline 1 & $\mathrm{Et}_{3} \mathrm{SiH}$ & 0.41 & 40 & 2 & 91 & 92 & 6 & 2 & 36 & 18 \\
\hline 2 & $\mathrm{Et}_{3} \mathrm{SiH}$ & 0.41 & 60 & 25 & 93 & 38 & 60 & 2 & 37 & 1.9 \\
\hline 3 & $\mathrm{Ph}_{3} \mathrm{SiH}$ & 1.64 & 40 & 2 & 80 & 100 & 0 & 0 & 32 & 16 \\
\hline 4 & $\mathrm{Ph}_{3} \mathrm{SiH}$ & 1.64 & 100 & 24 & 65 & 0 & 100 & 0 & 26 & 1.1 \\
\hline 5 & $\begin{array}{c}\left(\mathrm{Me}_{3} \mathrm{SiO}\right)_{2-} \\
\mathrm{Si}(\mathrm{Me}) \mathrm{H}\end{array}$ & 0.38 & 60 & 20 & 87 & 100 & 0 & 0 & 35 & 1.8 \\
\hline 6 & $\begin{array}{c}\left(\mathrm{Me}_{3} \mathrm{SiO}\right)_{2-} \\
\mathrm{Si}(\mathrm{Me}) \mathrm{H}\end{array}$ & 0.38 & 60 & 40 & 100 & 0 & 100 & 0 & 40 & 1.0 \\
\hline 7 & $(\mathrm{EtO})_{3} \mathrm{SiH}$ & 0.79 & 40 & 2 & 0 & - & - & - & - & - \\
\hline 8 & $(\mathrm{EtO})_{3} \mathrm{SiH}$ & 0.79 & 100 & 24 & 63 & - & 100 & - & 25 & 1.0 \\
\hline 9 & TMDS & 0.11 & 70 & 50 & $100^{[\mathrm{e}]}$ & uni & lentif & & - & - \\
\hline 10 & PMHS & 0.01 & 60 & 40 & $100^{[\mathrm{e}]}$ & & oduct & & - & - \\
\hline
\end{tabular}

[a] According to ref. 12 and www.sigmaaldrich.com. [b] determined by ${ }^{1} \mathrm{H}$ NMR using 1,3,5trimethoxybenzene as an internal reference. [c] Turnover number $=$ mol of product $/ \mathrm{mol}$ of catalyst. $[\mathrm{d}]$ Turnover frequency $=$ mol of product $/ \mathrm{mol}$ of catalyst/hour. [e] determined by GC and GC-MS .

The same tendency could be observed with para-methoxy and meta-methyl derivatives $\mathbf{6 c}$ and 6d with higher yields and reduced selectivities. By comparison, dimethylamino substrate $\mathbf{6 e}$ led to an opposite trend. Indeed, whereas the use of triethylsilane led to the $(E)$-alkenylsilane 
$\mathbf{8 e}$ in fair yield and selectivity, triphenylsilane afforded both (Z)- and (E)-products, 7e and $\mathbf{8 e}$, in a good yield. We could also notice alkyl substrates $\mathbf{6} \mathbf{f}$ and $\mathbf{6 g}$ displayed poor reactivities.

Table 3: substrate scope.

\begin{tabular}{|c|c|c|c|c|c|c|c|c|c|c|}
\hline & $\begin{array}{l}\overline{\overline{6 a-j}} \\
1 \text { eq. }\end{array}$ & $\begin{array}{c}+\left(\mathrm{R}^{3}\right)_{3} \mathrm{SiH} \frac{\text { Cat }}{\mathrm{T}} \\
1.2 \mathrm{eq} .\end{array}$ & $\begin{array}{l}(2.5 \mathrm{mo} \\
=, \mathrm{T}\left({ }^{\circ} \mathrm{C}\right) \\
\mathrm{t}(\mathrm{h})\end{array}$ & $\begin{array}{l}\mathrm{R}^{1} \\
7 \mathrm{a}-\mathrm{j}\end{array}$ & $\mathrm{R}^{2}$ & & $\begin{array}{l}\mathrm{Si}\left(\mathrm{R}^{3}\right)_{3} \\
\mathrm{R}^{2} \\
(E)\end{array}$ & $\begin{array}{r}\left.{ }^{3}\right)_{3} \mathrm{Si}^{\mathrm{R}^{1}} \\
9 \mathrm{a}-\mathrm{j}\end{array}$ & $=\mathrm{C}_{\mathrm{H}}^{\mathrm{H}}$ & \\
\hline Entry & & $\mathbf{R}_{1}$ & $\mathbf{R}_{2}$ & Silane & $\begin{array}{c}\mathbf{T} \\
\left({ }^{\circ} \mathbf{C}\right)\end{array}$ & $\begin{array}{c}\mathbf{t} \\
(\mathbf{h})\end{array}$ & $\begin{array}{l}\text { Yield } \\
(\%)^{[\mathrm{a}]}\end{array}$ & $\begin{array}{l}\text { Se } \\
7 \mathbf{a}-\mathbf{j} \\
(Z) /\end{array}$ & $\begin{array}{l}\text { a-j / } \\
\text { i) / (g }\end{array}$ & \\
\hline 1 & $6 \mathbf{6 a}$ & $\mathrm{Ph}$ & $\mathrm{H}$ & $\mathrm{Et}_{3} \mathrm{SiH}$ & 40 & 2 & 91 & 92 & 6 & 2 \\
\hline 2 & $6 \mathbf{a}$ & $\mathrm{Ph}$ & $\mathrm{H}$ & $\mathrm{Ph}_{3} \mathrm{SiH}$ & 40 & 2 & 80 & 100 & 0 & 0 \\
\hline 3 & $6 b$ & $p$-F- $\left(\mathrm{C}_{6} \mathrm{H}_{4}\right)$ & $\mathrm{H}$ & $\mathrm{Et}_{3} \mathrm{SiH}$ & 40 & 2 & 74 & 93 & 5 & 2 \\
\hline 4 & $6 \mathbf{b}$ & $p$-F- $\left(\mathrm{C}_{6} \mathrm{H}_{4}\right)$ & $\mathrm{H}$ & $\mathrm{Ph}_{3} \mathrm{SiH}$ & 40 & 2 & 22 & 0 & 100 & 0 \\
\hline 5 & $6 c$ & $p-\mathrm{MeO}-\left(\mathrm{C}_{6} \mathrm{H}_{4}\right)$ & $\mathrm{H}$ & $\mathrm{Et}_{3} \mathrm{SiH}$ & 40 & 2 & 86 & 69 & 30 & 1 \\
\hline 6 & $6 c$ & $p-\mathrm{MeO}-\left(\mathrm{C}_{6} \mathrm{H}_{4}\right)$ & $\mathrm{H}$ & $\mathrm{Ph}_{3} \mathrm{SiH}$ & 40 & 2 & 85 & 0 & 98 & 2 \\
\hline 7 & $6 d$ & $m-\mathrm{Me}-\left(\mathrm{C}_{6} \mathrm{H}_{4}\right)$ & $\mathrm{H}$ & $\mathrm{Et}_{3} \mathrm{SiH}$ & 40 & 2 & 93 & 93 & 5 & 2 \\
\hline 8 & $6 d$ & $m-\mathrm{Me}-\left(\mathrm{C}_{6} \mathrm{H}_{4}\right)$ & $\mathrm{H}$ & $\mathrm{Ph}_{3} \mathrm{SiH}$ & 40 & 2 & 100 & 0 & 95 & 5 \\
\hline 9 & $6^{e}$ & $p-\mathrm{NMe}_{2}-\left(\mathrm{C}_{6} \mathrm{H}_{4}\right)$ & $\mathrm{H}$ & $\mathrm{Et}_{3} \mathrm{SiH}$ & 40 & 2 & 81 & 19 & 81 & 0 \\
\hline 10 & $6^{\mathrm{e}}$ & $p-\mathrm{NMe}_{2}-\left(\mathrm{C}_{6} \mathrm{H}_{4}\right)$ & $\mathrm{H}$ & $\mathrm{Ph}_{3} \mathrm{SiH}$ & 40 & 12 & 86 & 55 & 41 & 4 \\
\hline 11 & $6 f$ & $n$-pentyl & $\mathrm{H}$ & $\mathrm{Et}_{3} \mathrm{SiH}$ & 40 & 2 & 33 & 0 & 100 & 0 \\
\hline 12 & $6 f$ & $n$-pentyl & $\mathrm{H}$ & $\mathrm{Ph}_{3} \mathrm{SiH}$ & 40 & 2 & 0 & - & - & - \\
\hline 13 & $6 \mathrm{~g}$ & cyclopropyl & $\mathrm{H}$ & $\mathrm{Et}_{3} \mathrm{SiH}$ & 40 & 2 & 0 & - & - & - \\
\hline 14 & $6 \mathrm{~g}$ & cyclopropyl & $\mathrm{H}$ & $\mathrm{Ph}_{3} \mathrm{SiH}$ & 40 & 2 & 0 & - & - & - \\
\hline 15 & $6 h$ & $\mathrm{CO}_{2} \mathrm{Et}$ & $\mathrm{H}$ & $\mathrm{Et}_{3} \mathrm{SiH}$ & 40 & 2 & $13^{[\mathrm{b}]}$ & 100 & 0 & 0 \\
\hline 16 & $6 h$ & $\mathrm{CO}_{2} \mathrm{Et}$ & $\mathrm{H}$ & $\mathrm{Ph}_{3} \mathrm{SiH}$ & 40 & 2 & 0 & - & - & - \\
\hline 17 & $6 \mathbf{i}$ & $\mathrm{Ph}$ & $\mathrm{CO}_{2} \mathrm{Et}$ & $\mathrm{Et}_{3} \mathrm{SiH}$ & 80 & 20 & $62^{[\mathrm{c}]}$ & 42 & 58 & - \\
\hline 18 & $\mathbf{6 i}^{[\mathrm{d}]}$ & $\mathrm{Ph}$ & $\mathrm{CO}_{2} \mathrm{Et}$ & $\mathrm{Et}_{3} \mathrm{SiH}$ & 80 & 20 & 6 & 100 & 0 & 0 \\
\hline 19 & $6 \mathbf{i}$ & $\mathrm{Ph}$ & $\mathrm{CO}_{2} \mathrm{Et}$ & $\mathrm{Ph}_{3} \mathrm{SiH}$ & 80 & 20 & 0 & - & - & - \\
\hline 20 & $\mathbf{6 j}$ & $\mathrm{Ph}$ & $\mathrm{Me}$ & $\mathrm{Et}_{3} \mathrm{SiH}$ & 80 & 20 & $35^{[\mathrm{e}]}$ & 0 & 100 & 0 \\
\hline 21 & $\mathbf{6 j}^{[\mathrm{d}]}$ & $\mathrm{Ph}$ & $\mathrm{Me}$ & $\mathrm{Et}_{3} \mathrm{SiH}$ & 80 & 20 & 8 & 50 & 50 & 0 \\
\hline 22 & $6 \mathbf{j}$ & $\mathrm{Ph}$ & $\mathrm{Me}$ & $\mathrm{Ph}_{3} \mathrm{SiH}$ & 80 & 20 & 0 & - & _- & - \\
\hline
\end{tabular}

[a] determined by ${ }^{1} \mathrm{H}$ NMR using 1,3,5-trimethoxybenzene as an internal reference and by GC. [b] same result in $20 \mathrm{~h}$ and $14 \%$ yield of $(E)$-selectivity if $80^{\circ} \mathrm{C}$ during $20 \mathrm{~h}$. [c] mixture of $\alpha-(E)$ - and $\alpha$ (Z)-products as respect to phenyl substituent. [d] in $\mathrm{CH}_{3} \mathrm{CN}$. [e] mixture of $\alpha$ - and $\beta$ - $(E)$-products as respect to phenyl substituent. 
Indeed, no reaction was observed with reagent $\mathbf{6 g}$ and the hydrosilylation of $\mathbf{6} \mathbf{f}$ proceeded only with the use of triethylsilane to lead to the $(E)$-product $\mathbf{8 f}$ in a low yield. Ethylpropiolate 6h displayed also a poor reactivity independently of the reaction time and temperature. Finally, the hydrosilylation of internal alkynes $\mathbf{6 i}$ and $\mathbf{6 j}$ was investigated. If no reactions were observed while using triphenylsilane, modest to average yields were obtained with triethylsilane and the use of acetonitrile as a solvent resulted also in lower reactivities. Reagent $6 \mathbf{i}$ led to both $(Z)$ - and $(E)$-products, $\mathbf{7 i}$ and $\mathbf{8 i}$, in a fair yield, and substrate $\mathbf{6 j}$ afforded exclusively $(E)$-products $\mathbf{8 j}$ in a modest yield.

As a preliminary study regarding the possible active species involved in the catalytic process of such alkyne hydrosilylation reactions [3s, 13, 14], we performed an analysis by electrospray ionization mass spectrometry on the reaction mixture obtained from the quantitative reaction of phenylacetylene 6a and complex 2 (Scheme 3, Figure 1).

Along this study, complex $\mathbf{2}$ had to be preferred to $\mathbf{1}$ because of its higher stability when analysed in methanol by mass spectrometry. Species $\mathbf{1 0}$ and $\mathbf{1 1}$ could be characterized unambiguously along with complexes 12 and 13a. Hence, if complex 10 resulted from a single 1,2-insertion of terminal alkyne $\mathbf{6 a}$ into the iridium- $\mathrm{C}_{\mathrm{Ar}}$ bond of complex $\mathbf{2}$, species $\mathbf{1 1}$ was issued from a double 1,2-insertion of $\mathbf{6 a}$ and no vinylidene rearrangement/1,1-insertion could be evidenced. Our previous studies on tandem hydroamination and hydrosilylation/protodesilylation reactions demonstrated complex $\mathbf{1 1}$, once isolated, had no catalytic activity [5]. Hence, single and double 1,2-insertion of terminal alkyne 6a proved to compete, one leading to an active catalyst and the other to an inert species. Otherwise, complex 13a and complex 12 which had been previously linked to the catalyst resting state [7] were also observed.

\section{Scheme 3.}

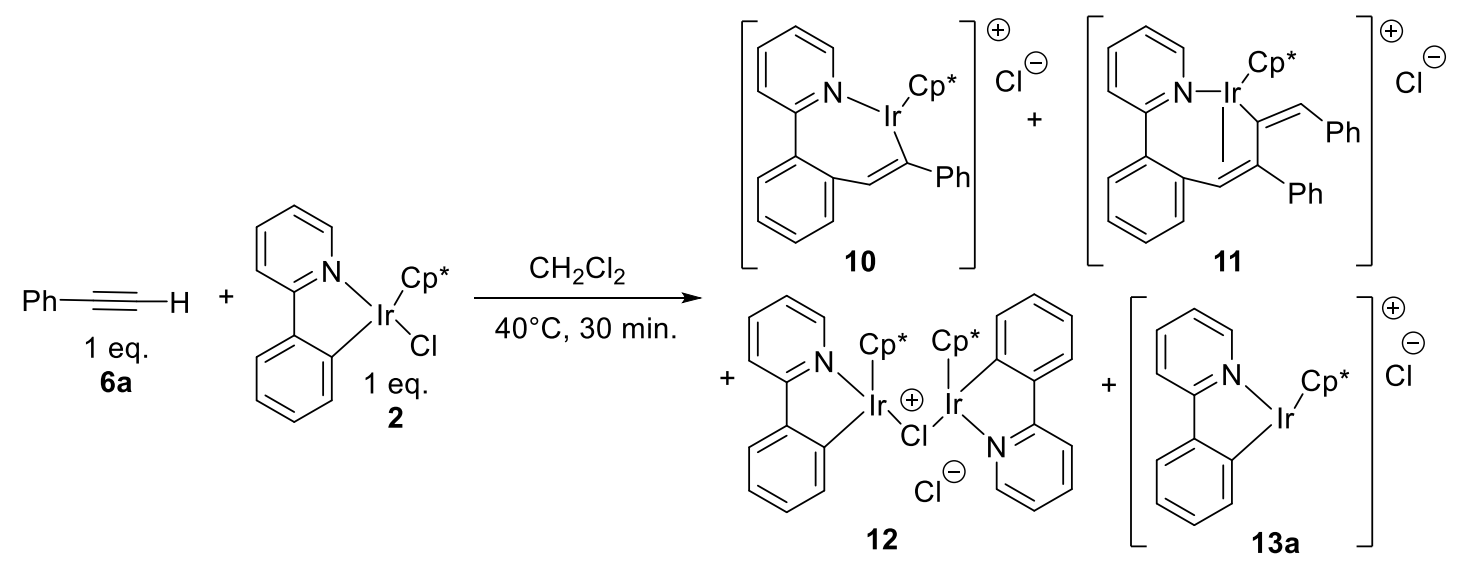


Figure 1. ESI(+)-MS analysis in methanol of the crude mixture resulting from the catalytic hydrosilylation of reagent $\mathbf{6 a}$.

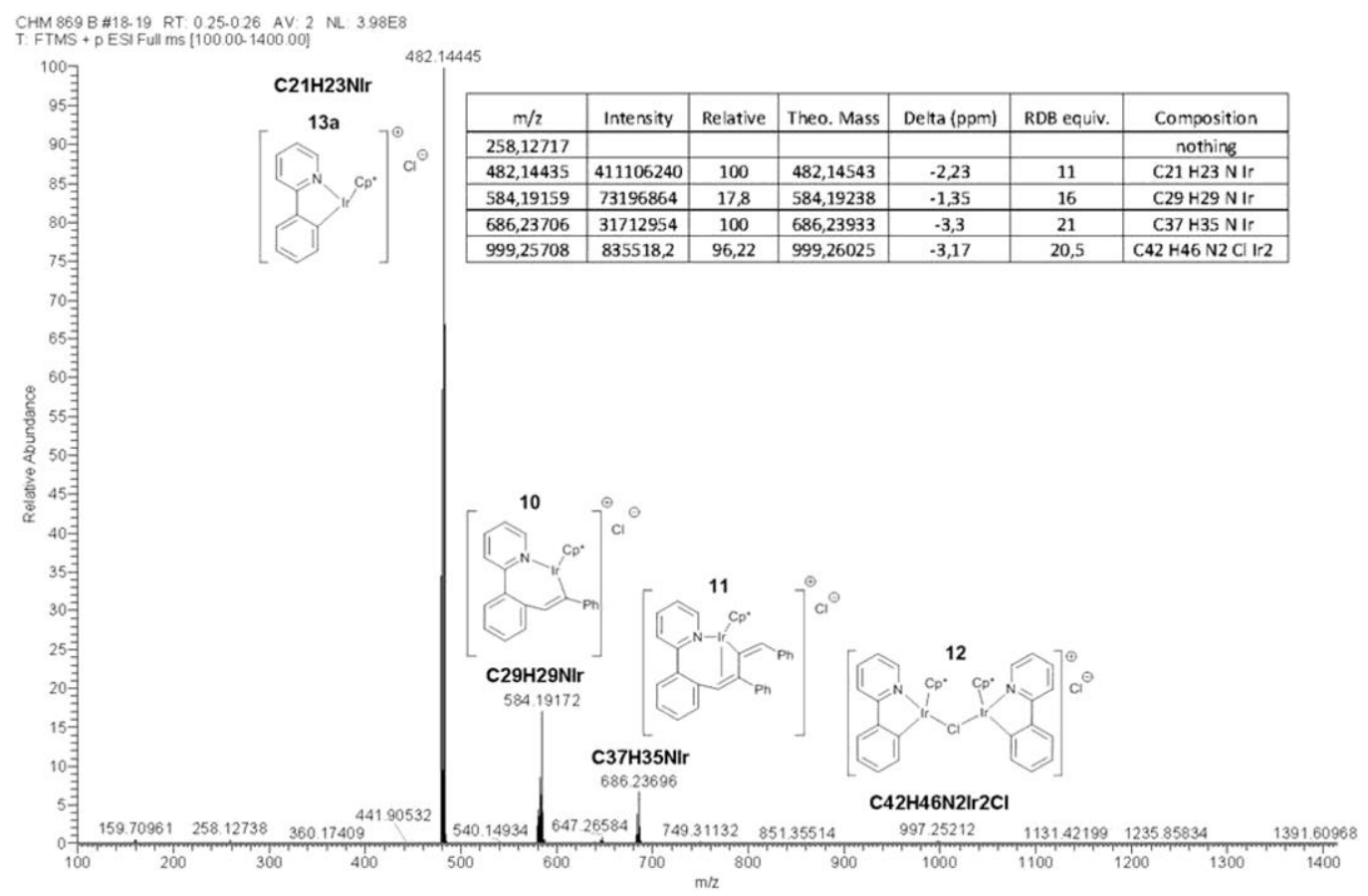

Another analysis by electrospray ionization mass spectrometry was performed on the crude mixture resulting from the quantitative reaction of iridium(III) complex $\mathbf{2}$ with internal alkyne 6i (Scheme 4, Figure 2). The use of silver tetrafluoroborate was shown to be critical to stabilize the formed species. If complex $\mathbf{1 3 b}$ appeared as the first reaction intermediate linked to the catalyst resting state [7], the main species observed at $\mathrm{m} / \mathrm{w} 656$ was likely to be complex $\mathbf{1 4}$ and/or $\mathbf{1 5}$ as the result of a single 1,2-insertion of internal alkyne $\mathbf{6 i}$ into complex 2 iridium- $\mathrm{C}_{\mathrm{Ar}}$ bond.

Scheme 4. Reaction of complex 2 with $\mathrm{AgBF}_{4}$ and phenylpropiolate.

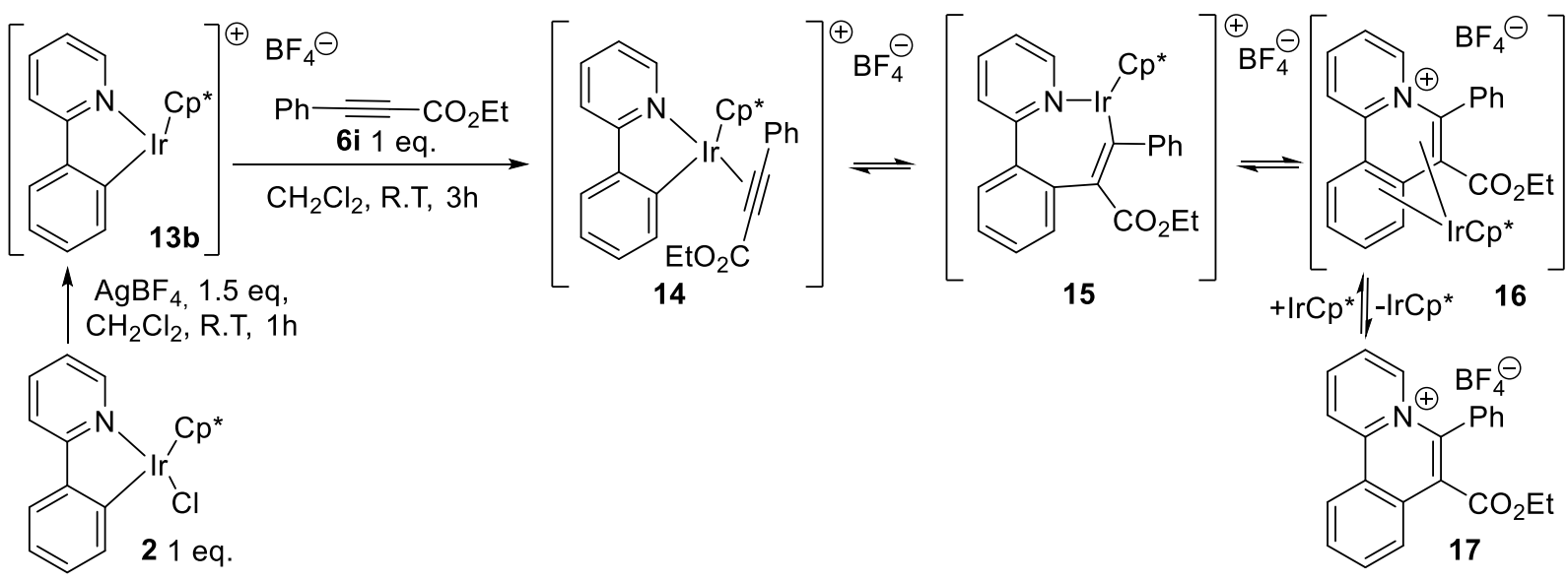


Figure 2. ESI(+)-MS analysis in methanol of the crude mixture resulting from the stoechiometric hydrosilylation of reagent $\mathbf{6 i}$.

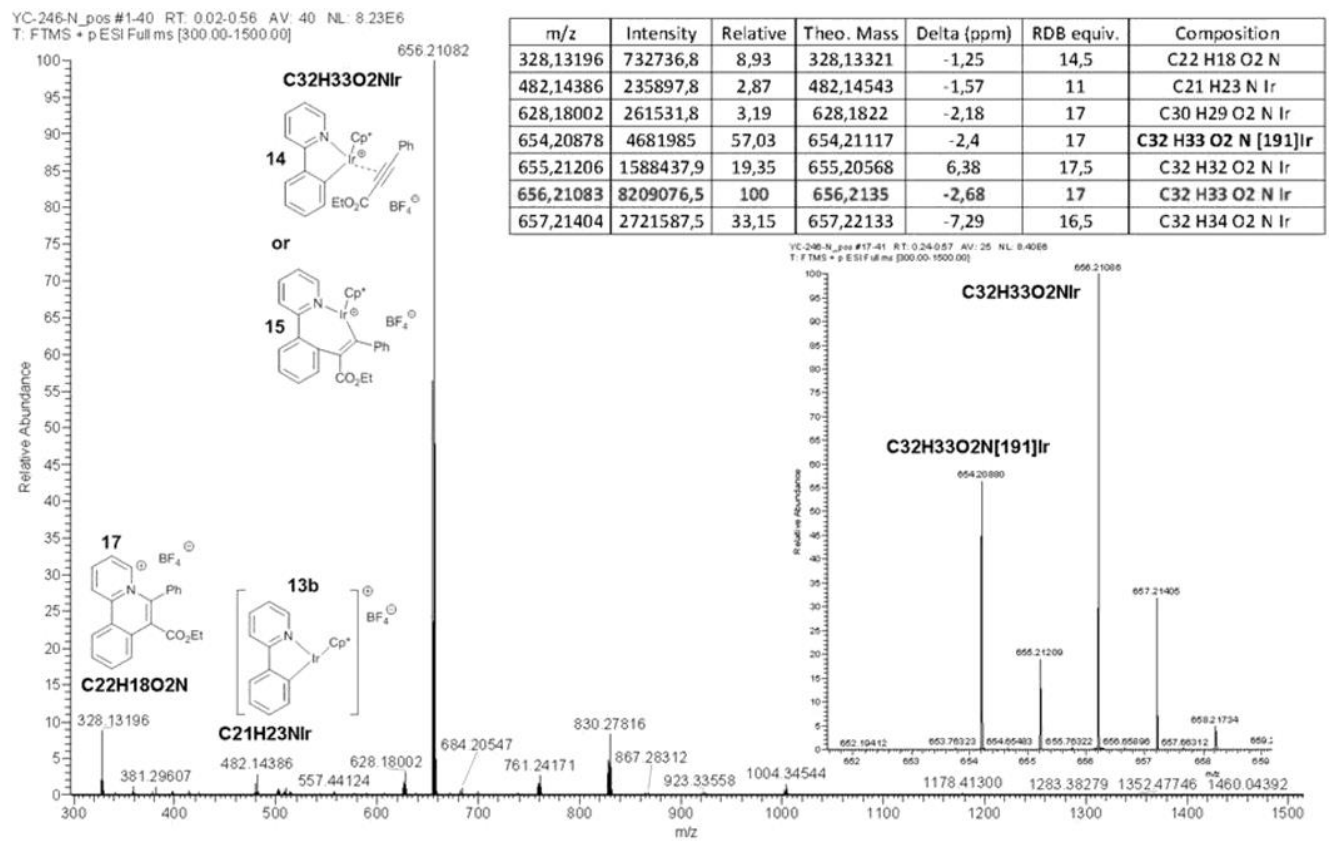

In addition, thanks to the stabilizing effect of tetrafluoroborate anion, minor species $\mathbf{1 7}$ was observed at m/w 328 and confirmed by X-ray diffraction analysis. Indeed, characterization of single crystals grown by diffusion of the reaction crude mixture (dichloromethane solution) in hexane helped to confirm the synthesis of species 17 (Figure 3, Table 4). That compound shall be prepared from complex $\mathbf{1 5}$ by, first, the formation of intermediate 16, which is a pyridoisoquinolinium moiety bound to the iridium center and, second, the release of pentamethylcyclopentadienyl iridium(III) fragment (Scheme 3). It is worth to note such reaction pathway was already observed when pentamethylcyclopentadienyl rhodium(III) complexes and $\mathrm{O}_{2}$ were used to catalyse oxidative $\mathrm{C}-\mathrm{H}$ activation/annulation reactions and produce various related isoquinolinium salts [15].

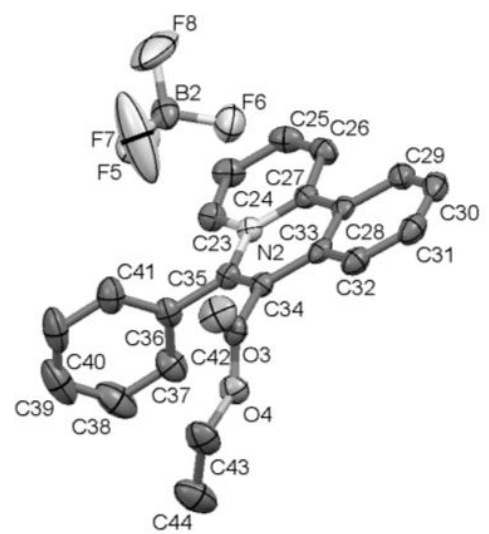

Figure 3. Ortep plot of $\mathbf{1 7}$ in the solid state. Thermal ellipsoids are drawn at a $50 \%$ probability level. Hydrogen atoms are omitted for clarity. CCDC 1473938 [16]. 
On the whole, if isoquinolinium salt $\mathbf{1 7}$ could be synthesised to the detriment of the catalytic hydrosilylation of alkynes, its characterization confirmed a single 1,2-insertion of internal alkyne into the catalyst iridium- $\mathrm{C}_{\mathrm{Ar}}$ bond was likely to occur. However, we could not find evidences of a double 1,2-insertion of internal alkynes or of a vinylidene rearrangement/1,1insertion. Hence, the reaction mechanism shall start by the insertion of alkyne reagent into the iridium- $\mathrm{C}_{\mathrm{Ar}}$ bond of the dechlorinated species $\mathbf{A}$ (Scheme 5).

Scheme 5. Proposed reaction mechanism.

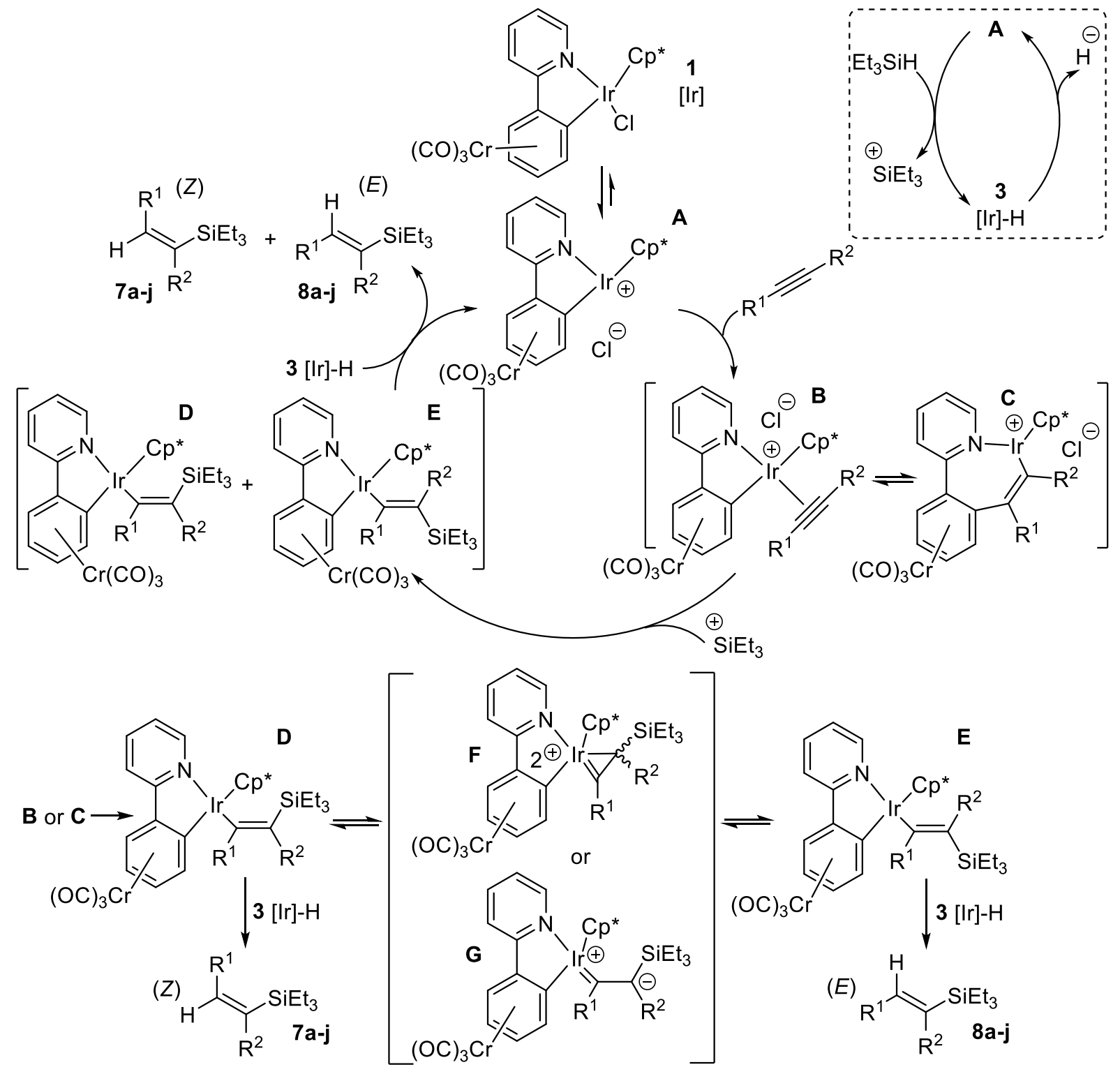

While a first equivalent of $\mathbf{A}$ inserts the alkyne reagent forming species $\mathbf{B}$ and $\mathbf{C}$, a second equivalent of $\mathbf{A}$ reacts with triethylsilane to afford iridium hydride complex $\mathbf{3}$ (Schemes 1 and 5) and triethylsilyl cation. The latter can then react with species $\mathbf{B}$ and $\mathbf{C}$ to lead to intermediates $\mathbf{D}$ and $\mathbf{E}$ which react further with hydride $\mathbf{3}$ to form $(Z)$ - and $(E)$-alkenylsilane 
products and release cationic iridium species A. If the low reactivity and selectivity observed for the hydrosilylation of internal alkynes may be related to their implicit steric hindrance and the possible formation of isoquinolinium salts, the selective synthesis of $(Z)$-alkenylsilanes from terminal alkynes proved to depend on both electronic and steric parameters of the substrates as well as on the reaction temperature (Tables 2 and 3, Scheme 5). According previous studies on iridium and rhodium catalysts [13c-e], (Z)-alkenylsilanes $7 \mathbf{a}-\mathbf{j}$ shall be the kinetic products formed through anti-additions leading to intermediates D (Scheme 5). Isomerization appeared privileged by high reaction temperature and time (Table 1). It may occur through $\eta^{2}$-vinyl species $\mathbf{F}$ or zwitterionic carbenes $\mathbf{G}$ to generate intermediates $\mathbf{E}$ which shall then react with iridium hydride $\mathbf{3}$ and afford $(E)$-alkenylsilanes $\mathbf{8 a - j}$ as the thermodynamic products (Scheme 5).

\section{Conclusion}

Pentamethylcyclopentadienyl iridium(III) metallacycles were shown to catalyse the hydrosilylation of alkynes using triethylsilane and no additive. The reactions could proceed rapidly and efficiently at low catalyst loading and under mild conditions. If the catalyses starting from terminal alkynes led selectively to $(Z)$-alkenylsilanes in high yields, reactions were less efficient and selective starting from internal alkynes due to steric hindrance and the possible formation of isoquinolinium salts. Isomerization from $(Z)$ - to $(E)$-alkenylsilanes appeared privileged by high reaction temperature and time. A study by mass spectrometry showed single and double alkyne 1,2-insertion could take place into the catalyst iridiumcarbon bond but no vinylidene rearrangement/1,1-insertion could be evidenced. Whereas a single insertion was observed for internal alkynes, a double 1,2-insertion was possible using terminal alkynes but led to an inert catalytic species.

\section{Experimental section}

\subsection{General data}

All solvents were dried using standard methods. All commercial reagents were used as received unless otherwise stated. Unless stated, all reactions were carried out under a dry nitrogen atmosphere. ${ }^{1} \mathrm{H}(300 \mathrm{MHz})$ and ${ }^{13} \mathrm{C}(75 \mathrm{MHz})$ spectra were acquired on a Bruker Avance spectrometer. Chemical shifts are reported downfield of $\mathrm{Me}_{4} \mathrm{Si}$ in ppm and coupling constants are expressed in Hz. Gas chromatography analyses were done on GC Shimadzu 
2010+ with FID detectors using Supelco SPB-5 column (30 m, $0.25 \mathrm{~mm}, 0.25 \mu \mathrm{m})$ and with nitrogen as gas carrier. GC-MS analyses were performed on a Shimadzu QP2010+ (EI mode) using Supelco column SLBTM-5ms (30 m, $0.25 \mathrm{~mm}, 0.25 \mu \mathrm{m})$. Analytical thin layer chromatography (TLC) was performed on Merck pre-coated $0.20 \mathrm{~mm}$ silica gel Alugram Sil 60 G/UV254 plates. Flash chromatography was carried out with Macherey silica gel (Kielselgel 60). MS-ESI and HRMS-ESI analyses were performed at CUMA-University Lille Nord de-France.

Table 4. Crystal data and structure refinement compound 17.

\begin{tabular}{|c|c|}
\hline & Compound 17 CCDC \\
\hline Temperature & $173 \mathrm{~K}$ \\
\hline Empirical formula & $\mathrm{C}_{22} \mathrm{H}_{18} \mathrm{NO}_{2} \mathrm{BF}_{4}$ \\
\hline Formula weight & 415.18 \\
\hline Wavelength & $0.71073(\operatorname{MoK} \alpha)$ \\
\hline Crystal system & Monoclinic \\
\hline Space group & $\mathrm{P} 21 / \mathrm{c}$ \\
\hline $\mathrm{a}(\AA)$ & $27.6525(14)$ \\
\hline $\mathrm{b}(\AA)$ & $10.2341(5)$ \\
\hline$c(\AA)$ & $14.1072(7)$ \\
\hline$\alpha\left(^{\circ}\right)$ & 90 \\
\hline$\beta\left({ }^{\circ}\right)$ & $102.6830(10)$ \\
\hline$\gamma\left(\left(^{\circ}\right)\right.$ & 90 \\
\hline $\operatorname{Volume}\left(\AA^{3}\right)$ & $3894.9(3)$ \\
\hline $\mathrm{Z}$ & 8 \\
\hline Crystal dim (mm) & $0.40 \times 0.25 \times 0.18$ \\
\hline Density (g.cm $\left.{ }^{-3}\right)$ & 1.416 \\
\hline Absorption coefficient & $0.115 \mathrm{~mm}^{-1}$ \\
\hline Absorption (max. and min. transmission) & 0.7458 and 0.6373 \\
\hline $\mathrm{F}(000)$ & 1712 \\
\hline $2 \theta$ limits (deg) & 1.510 to 29.050 \\
\hline Limits $h k l$ & $-37,37 /-13,13 /-19,19$ \\
\hline Reflections collected & 31007 \\
\hline Independent reflections & $10348[\mathrm{R}($ eq. $)=0.0841]$ \\
\hline Num. of var. & 543 \\
\hline GOF & 0.876 \\
\hline Final $\mathrm{R}$ indices & $\mathrm{R}=0.0552, \mathrm{wR}=0.1293$ \\
\hline $\mathrm{R}$ indices (all data) & $\mathrm{R}_{\mathrm{all}}=0.1593, \mathrm{w}_{\mathrm{all}}=0.1652$ \\
\hline
\end{tabular}

\subsection{General procedure for the catalysis}

Under nitrogen, alkyne reagent $(0.15 \mathrm{mmol}, 1$ eq. $)$ and selected iridium(III) catalyst ( $\mathrm{x}$ mol\%) were introduced in a Schlenk tube along with internal reference 1,3,5trimethoxybenzene ( 1 eq.). TCE solvent $(2 \mathrm{~mL})$ was added followed by silane reagent 
( $0.18 \mathrm{mmol}, 1.2$ eq.). The reaction mixture was then heated at the selected temperature under stirring. In order to follow the progress of the reaction, aliquots $(0.1 \mathrm{~mL})$ were taken at defined times, filtered through Celite with a $\mathrm{CH}_{2} \mathrm{Cl}_{2}$ wash $(3 \mathrm{~mL})$, evaporated under vacuum and analysed by ${ }^{1} \mathrm{H}$ NMR.

\section{Acknowledgements}

The Université Lille 1 and Région Nord-Pas de Calais are acknowledged for a PhD fellowship (Y. C.). The Agence Nationale de la Recherche (project ANR-10-BLAN-0736 administered by the University of Strasbourg) is thanked for a $\mathrm{PhD}$ funding (C. W.). The CNRS, the Chevreul Institute (FR 2638), the Ministère de l'Enseignement Supérieur et de la Recherche, the Région Nord - Pas de Calais and the FEDER are acknowledged for supporting and funding partially this work. Mrs C. Delabre (UCCS) is thanked for GC and GC-MS analyses. Mrs N. Duhal and C. Lenglart (CUMA, Lille University) are thanked for HRMS analyses.

\section{References:}

[1] (a) H.-U. Blaser, A. Schnyder, H. Steiner, F. Rössler, P. Baumeister, In Handbook of Heterogeneous Catalysis; Wiley-VCH Verlag GmbH \& Co. KGaA: Weinheim, Germany, 2008; pp 3284-3308. (b) D. Heller, A. H. De Vries, J. G. De Vries, In Handbook of Homogeneous Hydrogenation; de J. G. Vries, C. J. Elsevier, Eds.; Wiley-VCH: Weinheim, Germany, 2007; Vol. 3, pp 1483-1516. (c) A. Molnar, A. Sarkany, M. Varga, J. Mol. Catal. A: Chem. 173 (2001) 185-221.

[2] By hydrogenation: (a) S. Furukawa, T. Komatsu, ACS Catal. 6 (2016) 2121-2125; (b) K. C. Szeto, W. Sahyoun, N. Merle, J. L. Castelbou, N. Popoff, F. Lefebvre, J. Raynaud, C. Godard, C. Claver, L. Delevoye, R. M. Gauvin, M. Taoufik, Catal. Sci. Technol. 6 (2016) 882-889; (c) T. Mitsudome, M. Yamamoto, Z. Maeno, T. Mizugaki, K. Jitsukawa, K. Kaneda, J. Am. Chem. Soc. 137 (2015) 13452-13455; (d) W. Y. Siau, Y. Zhang, Y. Zhao, Top. Curr. Chem. 327 (2012) 33-58; (e) Y. Lee, Y. Motoyama, K. Tsuji, S. H. Yoon, I. Mochida, H. Nagashima, ChemCatChem 4 (2012) 778-781; (f) H. Sajiki, S. Mori, T. Ohkubo, T. Ikawa, A. Kume, T. Maegawa, Y. Monguchi, Chem. Eur. J. 14 (2008) 5109-5111; (g) J. J. Brunet, P. J. Caubere, J. Org. Chem. 49 (1984) 4058-4060; (h) J. Rajaram, A. P. S. Narula, H. P. S. Chawla, S. Dev, Tetrahedron 39 (1983) 2315-2322; (i) H. Lindlar, R. Dubuis, Organic Syntheses 46 (1966) 89-92; (j) H. Lindlar, Helv. Chim. Acta 35 (1952) 446-456. 
[3] By hydrosilylation: (a) M. Iglesias, M. Aliaga-Lavrijsen, P. J. Sanz Miguel, F. J. Fernández-Alvarez, J. J. Pérez-Torrente, L. A. Oro, Adv. Synth. Catal. 357 (2015) 350354; (b) Z. Mo, J. Xiao, Y. Gao, L. Deng, J. Am. Chem. Soc. 136 (2014) 17414-17417; (c) M. Iglesias, P. J. Sanz Miguel, V. Polo, F. J. Fernández-Alvarez, J. J. Pérez-Torrente, L. A. Oro, Chem. Eur. J. 19 (2013) 17559-17566; (d) S. Ding, L.-J. Song, L. W. Chung, X. Zhang, J. Sun, Y.-D. Wu, J. Am. Chem. Soc. 135 (2013) 13835-13842; (e) R. Cano, M. Yus, and D. J. Ramón, ACS Catal. 2 (2012) 1070-1078; (f) K. Igawa, D. Yoshihiro, N. Ichikawa, N. Kokan, K. Tomooka, Angew. Chem. Int. Ed. 51 (2012) 12745-12748; (g) M. Iglesias, M. Pérez-Nicolás, P. J. Sanz Miguel, V. Polo, F. J. Fernández-Alvarez, J. J. Pérez-Torrente, L. A. Oro, Chem. Commun. 48 (2012) 9480-9482; (h) Y. Sumida, T. Kato, S. Yoshida, T. Hosoya, Org. Lett. 14 (2012) 1552-1555; (i) W. A. Solomonsz, G. A. Rance, M. Suyetin, A. La Torre, E. Bichoutskaia, A. N. Khlobystov, Chem. Eur. J. 18 (2012) 13180-13187; (j) G. F. Silbestri, J. C. Flores, E. de Jesús, Organometallics 31 (2012) 3355-3360; (k) Y. Kawasaki, Y. Ishikawa, K. Igawa, K. Tomooka, J. Am. Chem. Soc. 133 (2011) 20712-20715; (1) L. Busetto, M. C. Cassani, C. Femoni, M. Mancinelli, A. Mazzanti, R. Mazzoni, G. Solinas, Organometallics 30 (2011) 5258-5272; (m) N. Kato, Y. Tamura, T. Kashiwabara, T. Sanji, M. Tanaka, Organometallics 29 (2010) 5274-5282; (n) B. Marciniec, H. Maciejewski, C. Pietraszuk and P. Pawluć in Hydrosilylation: A Comprehensive Review on Recent Advances, ed. B. Marciniec, Springer, Heidelberg, 2009; (o) J. J. Hu, F. Li, T. S. A. Hor, Organometallics 28 (2009) 1212-1220; (p) M. V. Jiménez, J. J. Pérez-Torrente, M. I. Bartolomé, V. Gierz, F. J. Lahoz, L. A. Oro, Organometallics 27 (2008) 224-234; (q) A. Hamze, O. Provot, J.-D. Brion, M. Alami, J. Organomet. Chem. 693 (2008) 2789-2797; (r) V. S. Sridevi, W. Y. Fan, W. K. Leong, Organometallics 26 (2007) 1157-1160; (s) L. Yong, K. Kirleis, H. Butenschön, Adv. Synth. Catal. 348 (2006) 833-836; (t) Y. Liu, S. Yamazaki, S. Yamabe, J. Org. Chem. 70 (2005) 556-561; (u) C. Menozzi, P. I. Dalko, J. Cossy, J. Org. Chem. 70 (2005) 10717-10719; (v) B. M. Trost, Z. T. Ball, Synthesis (2005) 853-887.

[4] (a) W. Iali, F. La Paglia, X.-F. Le Goff, D. Sredojevic , M. Pfeffer, J.-P. Djukic, Chem. Commun. 48 (2012) 10310-10312; (b) J.-P. Djukic, W. Iali, M. Pfeffer, X.-F. LeGoff, Chem. Eur. J. 18 (2012) 6063-6078; (c) J.-P. Djukic, W. Iali, M. Pfeffer, X.-F. LeGoff, Chem. Commun. 47 (2011) 3631-3633; (d) J.-P. Djukic, C. Boulho, D. Sredojevic, C. Scheeren, S. Zaric, L. Ricard, M. Pfeffer, Chem. Eur. J. 15 (2009) 10830-10842; (e) C. 
Scheeren, F. Maasarani, A. Hijazi, J.-P. Djukic, M. Pfeffer, S. D. Zaric, X.-F. LeGoff, L. Ricard, Organometallics 26 (2007) 3336-3345.

[5] W. Iali, F. La Paglia, X.-F. Le Goff, D. Sredojevic , M. Pfeffer, J.-P. Djukic, Chem. Commun. 48 (2012) 10310-10312.

[6] Y. Hu, L. Li, A. P. Shaw, J. R. Norton, W. Sattler, Y. Rong, Organometallics 31 (2012) $5058-5064$.

[7] Y. Corre, W. Iali, M. Hamdaoui, X. Trivelli, J.-P. Djukic, F. Agbossou-Niedercorn, C. Michon, Catal. Sci. Tech. 5 (2015) 1452-1458.

[8] (a) C. Michon, K. MacIntyre, Y. Corre, F. Agbossou-Niedercron, ChemCatChem 8 (2016) 1755-1762; (b) Y.-F. Han, G.-X. Jin, Chem. Soc. Rev. 43 (2014) 2799-2823.

[9] (a) W. Tang, C. Lau, X. Wu, J. Xiao, Synlett 25 (2014) 81-84; (b) J. Wu, J. H. Barnard, Y. Zhang, D. Talwar, C. M. Robertson, J. Xiao, Chem. Commun. 49 (2013) 7052-7054; (c) B. Villa-Marcos, W. Tang, X. Wu, J. Xiao, Org. Biomol. Chem. 11 (2013) 6934-6939.

[10] (a) H. Y. T. Chen, C. Wang, X. Wu, X. Jiang, C. R. A. Catlow, J. Xiao, Chem. Eur. J. 21 (2015) 16564-16577; (b) D. Talwar, H. L. Yi, E. Durham, J. Xiao, Chem. Eur. J. 21 (2015) 5370-5379; (c) D. Talwar, X. Wu, O. Saidi, N. P. Salguero, J. Xiao, Chem. Eur. J. 20 (2014) 12835-12842; (d) S. Sabater, M. Baya, J. A. Mata, Organometallics 33 (2014) 6830-6839; (e) Y. Wei, D. Xue, Q. Lei, C. Wang, J. Xiao, Green Chem. 15 (2013) 629634; (f) N. Pannetier, J.-B. Sortais, J.-T. Issenhuth, L. Barloy, C. Sirlin, A. Holuigue, L. Lefort, L. Panella, J. G. de Vries, M. Pfeffer, Adv. Synth. Catal. 353 (2011) 2844-2852; (g) S. Arita, T. Koike, Y. Kayaki, T. Ikariya, Organometallics 27 (2008) 2795-2802.

[11] (a) Y. Ikeda, S. Kodama, N. Tsuchida, Y. Ishii, Dalton Trans. 44 (2015) 17448-17452; (b) M. Valencia, M. Martín-Ortiz, M. Gómez-Gallego, C. Ramírez de Arellano, M. A. Sierra, Chem. Eur. J. 20 (2014) 3831-3838; (c) D. L. Davies, O. Al-Duaij, J. Fawcett, K. Singh, Organometallics 29 (2010) 1413-1420; (d) L. Li, Y. Jiao, W. W. Brennessel, W. D. Jones, Organometallics 29 (2010) 4593-4605.

[12] D. Addis, S. Das, K. Junge, M. Beller, Angew. Chem. Int. Ed. 50 (2011) 6004-6011.

[13] (a) S. Sridevi, W. Y. Fan, W. K. Leong, Organometallics 26 (2007) 1157-1160; (b) C. Vicent, M. Viciano, E. Mas-Marzá, M. Sanaú, E. Peris, Organometallics 25 (2006) 37133720; (c) C.-H. Jun, R. H. Crabtree, J. Organomet. Chem., 447 (1993) 177-187; (d) I. Ojima, N. Clos, R. J. Donovan, P. Ingallina, Organometallics, 9 (1990) 3127-3133 ; (e) J. E. Hill, T. A. Nile, J. Organomet. Chem., 137 (1977) 293-300; (f) A. J. Chalk, J. F. Harrod, J. Am. Chem. Soc. 89 (1967) 1640-1647. 
[14] (a) M. Iglesias, F. J. Fernández-Alvarez, L. A. Oro, ChemCatChem, 6 (2014) 24862489; (b) T. T. Metsänen, P. Hrobárik, H. F. T. Klare, M. Kaupp, M. Oestreich, J. Am. Chem. Soc. 136 (2014) 6912-6915; (c) W. Wang, P. Gu, Y. Wang, H. Wei, Organometallics 33 (2014) 847-857; (d) M. Iglesias, P. J. Sanz-Miguel, V. Polo, F. J. Fernández-Alvarez, J. J. Pérez-Torrente, L. A. Oro, Chem. Eur. J. 19 (2013) 1755917566; (e) J. Yang, P. S. White, M. Brookhart, J. Am. Chem. Soc. 130 (2008) 1750917518.

[15] (a) C.-Z. Luo, P. Gandeepan, J. Jayakumar, K. Parthasarathy, Y.-W. Chang, C.-H. Cheng, Chem. Eur. J. 19 (2013) 14181-14186; (b) G. Zhang, L. Yang, Y. Wang, Y. Xie, H. Huang, J. Am. Chem. Soc. 135 (2013) 8850-8853.

[16] CCDC 1473938 for compound 17. Selected bond lengths (Å): C27-N2 1.383(3), C27C28 1.442(3), C28-C33 1.403(3), C33-C34 1.435(3), C34-C35 1.347(3), C35-N2 1.426(3). These data can be obtained free of charge from The Cambridge Crystallographic Data Centre via www.ccdc.cam.ac.uk/data_request/cif. 